\title{
Roles of thermospheric neutral wind and equatorial electrojet in pre-reversal enhancement, deduced from observations in Southeast Asia
}

\author{
P. Abadi1,2*, Y. Otsuka3 ${ }^{3}$ HuiXin Liu ${ }^{4}$, K. Hozumi5 , D. R. Martinigrum¹,6, P. Jamjareegulgarn7, Le Truong Thanh ${ }^{8}$, and \\ R. Otadoy 9 \\ 'Space Science Center, Indonesian National Institute of Aeronautics and Space (LAPAN), Bandung, Indonesia; \\ ${ }^{2} S c h o o l$ of Electrical Engineering, Telkom University, Jl. Telekomunikasi No. 1, Kab. Bandung 40257, Indonesia; \\ ${ }^{3}$ Institute for Space-Earth Environmental Research (ISEE), Nagoya University, Nagoya, Japan; \\ ${ }^{4}$ Department of Earth and Planetary Science, Kyushu University, Fukuoka, Japan; \\ ${ }^{5}$ National Institute of Information and Communications Technology, Tokyo, Japan; \\ ${ }^{6}$ Research Institute for Sustainable Humanosphere (RISH), Kyoto University, Kyoto, Japan; \\ ${ }^{7}$ King Mongkut's Institute of Technology Ladkrabang, Prince of Chumphon Campus, Chumphon, Thailand; \\ ${ }^{8}$ Institute of Geophysics, Vietnamese Academy of Science and Technology, Hanoi, Vietnam; \\ 'University of San Carlos, Cebu, Philippines
}

\section{Key Points:}

- Both eastward neutral wind and the equatorial electrojet (EEJ) are involved in the pre-reversal enhancement (PRE) mechanism, and these two parameters could influence the PRE magnitude in a balanced manner.

- A positive correlation between eastward neutral wind and PRE is deduced from the observation.

- The eastward neutral wind and the EEJ are independent of each other, and thus, these two parameters equivalently and independently contribute to increasing the PRE amplitude.

Citation: Abadi, P., Otsuka, Y., Liu, H. X., Hozumi, K., Martinigrum, D. R., Jamjareegulgarn, P., Thanh, L. T, and Otadoy, R. (2021). Roles of thermospheric neutral wind and equatorial electrojet in pre-reversal enhancement, deduced from observations in Southeast Asia. Earth Planet. Phys., 5(5), 387-396. http://doi.org/10.26464/epp2021049

\begin{abstract}
Previous studies have proposed that both the thermospheric neutral wind and the equatorial electrojet (EEJ) near sunset play important roles in the pre-reversal enhancement (PRE) mechanism. In this study, we have used observations made in the equatorial region of Southeast Asia during March-April and September-October in 2010-2013 to investigate influences of the eastward neutral wind and the EEJ on the PRE's strength. Our analysis employs data collected by the Gravity Field and Steady-State Ocean Circulation Explorer (GOCE) satellite to determine the zonal (east-west direction) neutral wind at an altitude of $\sim 250 \mathrm{~km}$ (bottomside $\mathrm{F}$ region) at longitudes of $90^{\circ}-130^{\circ} \mathrm{E}$ in the dusk sector. Three ionosondes, at Chumphon (dip lat.: $3.0^{\circ} \mathrm{N}$ ) in Thailand, at Bac Lieu (dip lat.: $1.7^{\circ} \mathrm{N}$ ) in Vietnam, and at Cebu (dip lat.: $3.0^{\circ} \mathrm{N}$ ) in Philippines, provided the data we have used to derive the PRE strength. Data from two magnetometers - at Phuket (dip lat.: $0.1^{\circ} \mathrm{S}$ ) in Thailand and at Kototabang (dip lat.: $10.3^{\circ} \mathrm{S}$ ) in Indonesia - were used to estimate the EEJ strength. Our study is focused particularly on days with magnetically quiet conditions. We have found that the eastward neutral wind and the EEJ are both closely correlated with the PRE; their cross-correlation coefficients with it are, respectively, 0.42 and 0.47 . Their relationship with each other is weaker: the cross-correlation coefficient between the eastward neutral wind and the EEJ is just 0.26 . Our findings suggest that both the eastward neutral wind and the EEJ near sunset are involved in the PRE mechanism. Based on the weak relationship between these two parameters, however, they appear to be significantly independent of each other. Thus, the wind and the EEJ are likely to be influencing the PRE magnitude independently, their effects balancing each other.
\end{abstract}

Keywords: equatorial ionosphere; thermosphere-ionosphere couple; pre-reversal enhancement; thermospheric neutral wind; equatorial electrojet

Correspondence to: P. Abadi, prayitno.abadi@lapan.go.id

Received 11 JAN 2021; Accepted 25 AUG 2021

Accepted article online 10 SEP 2021.

C 2021 by Earth and Planetary Physics.

\section{Introduction}

In the sunset equatorial ionosphere $\mathrm{F}$ region, the eastward electric field is enhanced before the electric field turns westward for the rest of the night. This enhancement of the eastward electric field in the evening equatorial ionosphere is widely termed the 
pre-reversal enhancement (PRE) phenomenon (Fejer, 1997). A major motivation in studying the PRE mechanism is that the PRE is one of the crucial factors in generating equatorial plasma bubbles (EPBs); EPBs can cause serious problems in the technologies employing trans-ionospheric radiowave propagation, such as the $\mathrm{GHz}$ frequency radiowaves used in the Global Navigation Satellite System (GNSS). EPBs are localized depletions of the plasma density in the nighttime equatorial and low-latitude ionosphere $\mathrm{F}$ regions. The irregularities (plasma density fluctuations) inside an EPB, with a spatial scale of hundreds of meters, can cause scintillation on $\mathrm{GHz}$ radio frequencies (Wernik and Liu $\mathrm{CH}, 1974$ ). In extreme cases, strong scintillations due to the strong amplitude of these plasma irregularities can result in the strong fading of radio waves; sometimes the disruption is great enough that GNSS signals cannot be tracked (loss-of-lock) (Seo et al., 2009). At the magnetic equator, a PRE-causing upward $E \times B$ plasma drift lifts the $F$ region plasma to higher altitudes where the Rayleigh-Taylor instability, which causes the EPB, grows rapidly (Kelley, 2009). Stronger PREs result in a higher probability that an EPB will occur (Huang CS and Hairston, 2015; Huang CS, 2018; Abadi et al., 2020). Therefore, studying the variability of the PRE phenomenon can assist understanding of the probability of EPB occurrence.

The PRE's dependencies on solar activity, geomagnetic activity, season, and longitude are well-known (Fejer et al., 1999). However, daily variations of the PRE magnitude remain poorly documented. The published literature (e.g., Eccles et al., 2015) suggests that both eastward neutral winds in the thermosphere and the eastward current associated with the equatorial electrojet (EEJ) in the evening sector are involved in the PRE mechanism. However, to investigate which parameter controls the day-to-day variability of the PRE magnitude, previous studies examined whether wind and EEJ influences could combine in a balanced manner or whether one of them predominates. Based on observations in November 2004 of a reversed PRE (downward vertical plasma drift) and counter electrojet in the equatorial ionosphere over Jicamarca, Peru, in association with the occurrence of a magnetic storm, Kelley et al. (2009) implied that the normal PRE, which causes upward vertical plasma drift, is likely to be controlled primarily by the EEJ current; they concluded that the influence of the wind is probably a secondary factor. By using numerical simulation, Eccles et al. (2015) reported that the influence of the eastward wind on the PRE mechanism through the $F$ region dynamo process could be the dominant factor in determining PRE magnitude when the solar terminator and magnetic meridian are aligned. However, by employing the Ground-to-topside Atmosphere and lonosphere for Aeronomy (GAIA) model, Ghosh et al. (2020) reported different results, concluding that in equinox season, in Southeast Asian longitudes where solar terminator and magnetic meridian are aligned, both the eastward wind and the EEJ have significant influence in determining the day-to-day variations of the PRE magnitude. Thus we have sought to use observational evidence to address the open question: Does either the eastward wind or the EEJ dominant in controlling the amplitude of the PRE on a daily basis? Or are both parameters important drivers of those amplitudes?

In this study, we have thus focused on the relationships between the eastward neutral wind and the PRE magnitude, between the EEJ and the PRE magnitude, and also between the two parameters themselves - the wind and the EEJ.

It was crucial that observations of the wind, the EEJ, and the PRE be simultaneous. To understand the role of the eastward neutral wind we needed to capture the activities of the thermospheric neutral wind and the ionosphere. Since the PRE is a phenomenon observed at fixed local time (an evening phenomenon), we sought observations of the neutral wind in the evening equatorial bottomside $\mathrm{F}$ region. Recently, the sun-synchronous Gravity Field and Steady-State Ocean Circulation Explorer (GOCE) satellite has flown in a meridional direction at an altitude of $\sim 250 \mathrm{~km}$ and has measured zonal (east-west direction) neutral wind using an accelerometer. GOCE wind data thus allowed us to observe, with less local time variation than other potential data sources, the zonal neutral wind near sunset in the bottomside $\mathrm{F}$ region with a high spatial resolution - approximately $77.5 \mathrm{~km}$ (Liu HX et al., 2016 ; 2017). For measurement of the EEJ, data from two magnetometers, one situated at the equator and the other situated in the off-equator, were used to derive the EEJ strength, by methods reported in previous studies (e.g., Dabas et al., 2003; Tulasi Ram et al., 2007; Uemoto et al., 2010). In this study, we thus are able to present simultaneous observations of the thermospheric neutral wind data, the EEJ strength, and the PRE magnitude to investigate statistically the roles of the zonal wind and the EEJ on the PRE magnitude in equinox seasons (March-April and September-October).

\section{Observations}

This study utilizes virtual height ( $h$ 'F) data from ionosondes, thermospheric neutral wind data by in-situ measurement from the GOCE satellite, and EEJ strength estimated by two magnetometers, one magnetometer situated in the equator and the other in the off-equator. In particular, this study focuses on data collected in the Southeast Asian longitude sector during March, April, September, and October of 2010 to 2013, when the solar terminator and magnetic meridian were approximately aligned in the Southeast Asian sector. Furthermore, we have deliberately restricted our analysis to data collected during magnetically quiet times - days when the maximum value of the $K p$ index was less than 3 in the interval 0-12 UT (around 7-19 local time/LT in the west of Southeast Asia).

The three ionosondes chosen for this study are installed at Chumphon (CPN; $99.4^{\circ} \mathrm{E}, 10.7^{\circ} \mathrm{N}$, dip latitude: $\left.3.0^{\circ} \mathrm{N}\right)$ in Thailand, at Bac Lieu (BCL; $105.7^{\circ} \mathrm{E}, 9.3^{\circ} \mathrm{N}$, dip latitude: $\left.1.5^{\circ} \mathrm{N}\right)$ in Vietnam, and at Cebu (CEB; $123.91^{\circ} \mathrm{E}, 10.4^{\circ} \mathrm{N}$, dip latitude: $3.0^{\circ} \mathrm{N}$ ) in the Philippines. Geographically, all three are located at roughly the same latitude but the longitudinal distances $C P N-B C L$ and $B C L-C E B$ are, respectively, $\sim 7^{\circ}$ and $\sim 18^{\circ}$. These ionosondes are part of the Southeast Asia Low-latitude lonospheric Network (SEALION) project (for details, see Maruyama et al., 2007). We employ data from these ionosondes to estimate the velocity of upward plasma drift near sunset, as a proxy for PRE magnitude. The ionosonde observations normally take place at a frequency sweep rate of $100 \mathrm{kHz} / \mathrm{s}$ between $2 \mathrm{MHz}$ and $30 \mathrm{MHz}$ with transmitting power of $20 \mathrm{~W}$. Therefore, complete transmitting and receiving of each observa- 
tion session takes 4 minutes and 40 seconds; the time resolution for recording each ionogram is thus $5 \mathrm{~min}$. Specifications of the SEALION ionosonde have been reported by Nozaki (2009).

We calculate the time derivative of $h^{\prime} \mathrm{F}$ at $3 \mathrm{MHz}\left(\mathrm{d} h^{\prime} \mathrm{F} / \mathrm{d} t\right)$ from 18:30 to 19:00 LT from the ionosondes to estimate the PRE magnitude. Note that "LT" in each ionosonde observation is the local time at the longitude of that ionosonde. In this study, we take into account some considerations in using the $h^{\prime} \mathrm{F}$ variation for estimating the PRE strength. We calculate $\mathrm{d} h^{\prime} \mathrm{F} / \mathrm{d} t$ only when the $h^{\prime} \mathrm{F}$ values are higher than $300 \mathrm{~km}$, to minimize the influence of the recombination process on the vertical motion of the plasma in the ionosphere $\mathrm{F}$ region (Bittencourt and Abdu, 1981). We exclude $h ' F$ data from times when equatorial spread-F (ESF) appears in the ionogram, because an ESF occurrence indicates the existence of ionospheric irregularities in the nighttime $\mathrm{F}$ region ionosphere. (When an ESF appears in an ionogram, the $h^{\prime} F$ is hardly scaled; thus, we could not determine the $h^{\prime} F$ in such instances.) We note that ESF occurrences usually appeared after 19 LT. Therefore, we select the time derivative of $h^{\prime} \mathrm{F}$ data in the interval of 18:30-19:00 LT at altitudes higher than $300 \mathrm{~km}$ to obtain the upward velocity of the equatorial bottomside $\mathrm{F}$ region as a proxy for PRE strength.

In this study, we deliberately used data from three ionosondes (CPN, BCL, and CEB) to allow our estimation of PRE strength to be as accurate as possible. As aforementioned, we derive vertical drift velocity of bottomside $F$ region from the ionosonde as a proxy for the PRE strength. When the vertical drift velocities could be derived from two or three ionosondes on a certain night, we have taken their average value as the PRE strength representation on such a night. When the vertical drift velocity could be derived from just a single ionosonde, we have been constrained to take this single vertical drift velocity as the PRE strength representation. To illustrate our method of employing ionosonde data to estimate PRE strength, Figure 1 displays the variations of $h^{\prime} F$ at $3 \mathrm{MHz}$ from 17:00 to 20:00 LT on 5 March 2011, obtained from the CPN (red curve), BCL (blue curve), and CEB (black curve) ionosondes. The $h$ 'F enhancement can be seen to begin at roughly the time of sunset. Furthermore, an ESF appears after 19:00 LT (cyan colors); so the time derivations of $h^{\prime} F$ from 18:30 to 19:00 LT, when the $h^{\prime} F$ values are higher than $300 \mathrm{~km}$ and before the appearance of the ESF, are employed to represent vertical upward drifts associated with the PRE. The values of PRE strength on 5 March 2011 are thus estimated as 30,34 , and $37 \mathrm{~m} / \mathrm{s}$, respectively, from ionosondes $C P N, B C L$, and CEB. We take their average, $\sim 34 \mathrm{~m} / \mathrm{s}$, as the PRE strength on 5 March 2011.

Our data characterizing the zonal neutral wind are derived from in-situ measurements made aboard the GOCE satellite. The GOCE satellite is a sun-synchronous satellite that orbits at an inclination of $\sim 97^{\circ}$ and moves with a speed of $\sim 7.7 \mathrm{~km} / \mathrm{s}$ at an altitude of $\sim 250 \mathrm{~km}$, flying in the dusk-dawn meridional plane (approximately 7 and 19 LT) (Liu HX et al., 2016, 2017). This satellite thus measures the zonal wind at a certain longitude always in the dusk-dawn sector and within a narrow window of local time. This is a merit of this study. We were able in this way to examine how the neutral wind influenced day-to-day variations in PRE magnitude at a nearly fixed local time in the evening sector. The neutral wind data from the GOCE satellite were recorded by its on- board accelerometer, which measures the total cross-track wind from the total acceleration (the summation of the inertial velocities of the spacecraft, the corotating atmosphere, and the neutral wind) (Doornbos et al., 2010).

The present study uses zonal neutral wind data collected at approximately 18-19 hours Local Solar Time (LST) during March-April and September-October from 2010 to 2013, when GOCE satellite paths were in the longitude range of $90^{\circ}-130^{\circ} \mathrm{E}$ and latitudes from $5^{\circ} \mathrm{N}$ to $15^{\circ} \mathrm{N}$ (magnetic latitudes between $5^{\circ} \mathrm{S}$ and $5^{\circ} \mathrm{N}$ ). Within that data set, we have limited our analysis specifically to data collected by the GOCE satellite simultaneously with the ionosonde observations of PRE strength. Furthermore, within each observation day's data, we calculate the average zonal wind velocity from data collected at geographic longitude and latitude intervals of $90^{\circ}-130^{\circ} \mathrm{E}$ and $5^{\circ} \mathrm{N}-15^{\circ} \mathrm{N}$, respectively, and in the time interval of 18-19 LST. We exclude data from days on which the zonal wind velocity's standard deviation exceeded $10 \%$, in order to minimize not only the measurement error but also the effects of latitudinal and temporal wind variations.

Figure 2 presents an example of the wind data along the satellite track over Southeast Asia on a representative day, 5 March 2011. The GOCE satellite measures the zonal wind around the magnetic equator. The path of the satellite on that day at an altitude of $\sim 250 \mathrm{~km}$ (indicated by black dots) is plotted on the geographical coordinate map in Figure 2a; the blue line indicates the magnetic equator in the Southeast Asian longitude sector. The zonal wind velocities at all satellite paths in Figure $2 \mathrm{a}$ are displayed in Figure $2 b$, which presents the velocities recorded in the narrow local time interval of 18.4-18.5 LST; note that all velocities are in the interval of $110-130 \mathrm{~m} / \mathrm{s}$; the average velocity is $\sim 122 \mathrm{~m} / \mathrm{s}$, with standard deviation of $\sim 4.2 \mathrm{~m} / \mathrm{s}$.

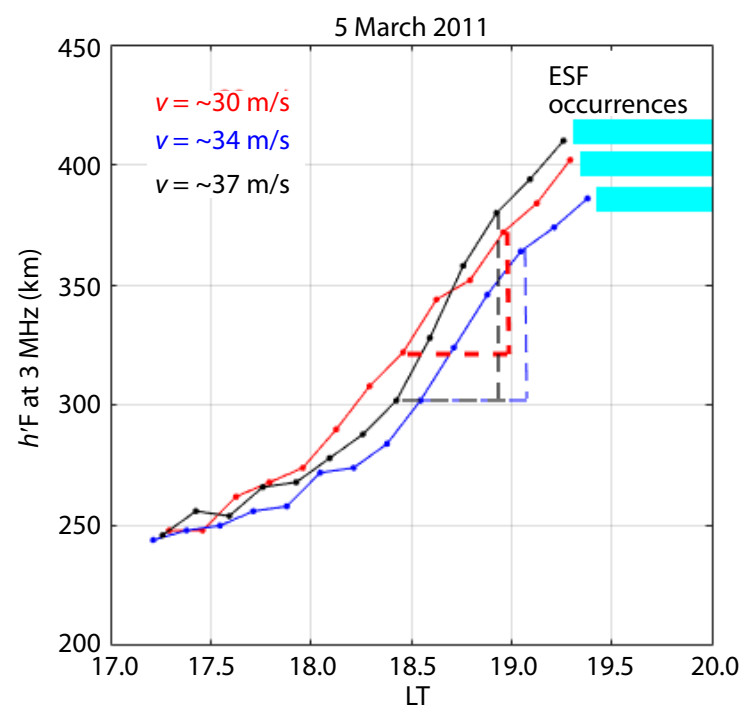

Figure 1. Temporal variations in $h^{\prime} \mathrm{F}$ scaled at $3 \mathrm{MHz}$ from the ionograms obtained by ionosondes at Chumphon (red curve), Bac Lieu (blue curve), and Cebu (black curve) on 5 March 2011. The averaged time derivative of $h^{\prime} \mathrm{F}$ from 18.5 to 19 LT (indicated by dashed lines) is calculated as a proxy for upward plasma drift in the $F$ region ionosphere due to the PRE phenomenon. 

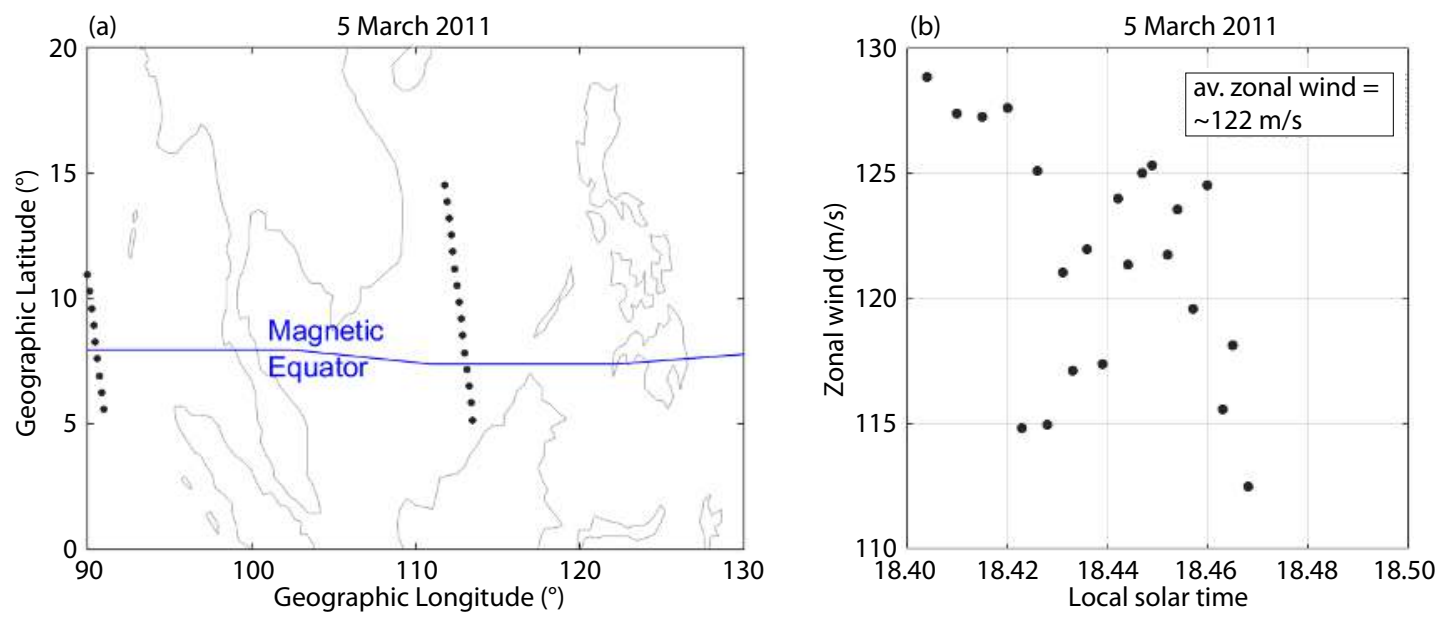

Figure 2. (a) Paths of the GOCE satellite (black dots) orbits at geographic longitudes of $90^{\circ} \mathrm{E}-130^{\circ} \mathrm{E}$ and latitudes of $5^{\circ}-15^{\circ} \mathrm{N}$ on $5 \mathrm{March} 2011$ from 18-19 LST. (b) The zonal neutral wind data measured by the GOCE satellite on those paths, plotted against local solar time (LST).

The zonal neutral wind experiences local time and latitudinal variation (see Raghavarao et al., 1991; Liu HX et al., 2009; Abadi et al., 2017). With a standard deviation of only $\sim 4.2 \mathrm{~m} / \mathrm{s}$ in the average of data recorded on the day in question, we believe it reasonable to estimate the influences of latitudinal and temporal variations in the wind data plotted in Figure $2 b$ to be $\sim 3 \%$ (in any case, less than 10\%). In this example, we therefore employ the value of $\sim 122 \mathrm{~m} / \mathrm{s}$ as the zonal wind speed in the evening thermosphere over Southeast Asia on that day, 5 March 2011.

To derive a proxy of EEJ strength, we use data from two magnetometers in the west of Southeast Asia, one located at the magnetic equator (at Phuket (PKT; $8.1^{\circ} \mathrm{N}, 98.3^{\circ} \mathrm{E}$, dip latitude: $0.1^{\circ} \mathrm{N}$ ) in Thailand), the other in the off-equator (at Kototabang (KTB; $0.2^{\circ} \mathrm{S}$, $100.3^{\circ} \mathrm{E}$, dip latitude: $10.0^{\circ} \mathrm{S}$ ) in Indonesia). Each magnetometer records the variation of the horizontal $(H)$ component of the geomagnetic field with a time resolution of $1 \mathrm{~min}$. The deviation of the $H$-component or $\Delta H$ in each station is calculated from the $\mathrm{H}$ component variation after subtracting the nighttime base level. In this study, we use for our analysis the hourly $\Delta H$ values derived from the 1-min values. The EEJ is derived from the differences between the hourly $\Delta H$ variations at PKT $\left(\Delta H_{\mathrm{PKT}}\right)$ (equator) and those at KTB ( $\Delta H_{\mathrm{KTB}}$ ) (off-equator). Uemoto et al. (2010), who employed the same magnetometers as used in this study and the Chumphon ionosonde, investigated the relations among the EEJ, the PRE, and occurrences of the EPB, and reported that the integrated EEJ (IEEJ) values a few hours before sunset are well-correlated with the strength of the PRE. We follow the method way of Uemoto et al. (2010) to derive the proxy of the EEJ; that is, we take the EEJ strength on a given day to be represented by the value of the IEEJ component in the time interval of 9-12 UT (roughly 16-19 LT in the west of Southeast Asia). To analyze the relationship between the EEJ and the PRE, we then employ the IEEJ and PRE obtained on the same day.

Figure 3 presents an example of how we derive the IEEJ strength on a representative day, from the hourly $\Delta H$ variations recorded at PKT and KTB. The red and black curves in Figure 3 show hourly $\Delta H$ variations from the PKT and KTB magnetometers, respectively, on that day, 5 March 2011. A measure of EEJ component variation on

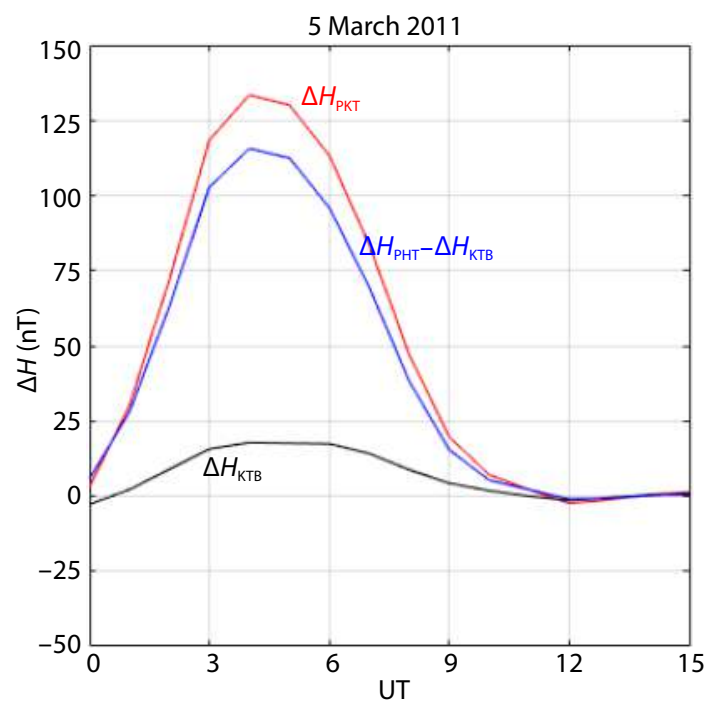

Figure 3. Hourly $\Delta H$ variations between magnetometer readings at PKT ( $\Delta H_{\mathrm{PKT}}$, red curve) and KTB ( $\Delta H_{\mathrm{KTB}}$, black curve) on 5 March 2011. The computation of hourly $\Delta H$ variations is explained in the main text. The blue line shows the EEJ component variation on that day, calculated as the difference between the red $\left(\Delta H_{\mathrm{PKT}}\right)$ and black $\left(\Delta H_{\mathrm{KTB}}\right)$ curves. The EEJ component integrated from 9 to 12 UT (IEEJ) is taken as the relevant EEJ strength on that day (integral of the blue curve over those hours).

that day is indicated by the blue curve, which presents the difference between the red and the black curves. As the blue curve indicates, the variation of the EEJ component, the sum of the EEJ values between 9 and 12 UT, represents the integrated EEJ (IEEJ) strength on this day; that is, the IEEJ value of $\sim 23 \mathrm{nT}$ represents the EEJ strength on 5 March 2011.

\section{Results}

During March-April and September-October from 2010 to 2013, we collected 187 days of ionosonde PRE data, 74 days of GOCE satellite measurements of zonal neutral winds, and 119 days of magnetometer data regarding IEEJ strength. These observations 
yielded PRE values ranging from $0 \mathrm{~m} / \mathrm{s}$ to $\sim 67 \mathrm{~m} / \mathrm{s}$; zonal neutral wind values ranging from $50 \mathrm{~m} / \mathrm{s}$ to $180 \mathrm{~m} / \mathrm{s}$. (note that positive values indicate zonal neutral winds that blew eastward); and IEEJ strengths falling within the interval of -30 to $128 \mathrm{nT}$. The intervals of daily $F_{10.7}$ (which indicate the level of solar activity) that occurred during the months included in this study ranged from 74 to 180 solar flux units (s.f.u).

The PRE is a phenomenon that is very sensitive to solar (Fejer et al., 1999) and magnetic (e.g., Carter et al., 2014) activity; the PRE may even be affected by the deviation between the terminator angles and the magnetic meridian (magnetic declination) that varies even within the same equinox season. Therefore, before we analyze the influence of the thermospheric wind and the EEJ on the PRE, we need to examine the effects of such other factors. From Burke et al. (2004), we use $a$ as an estimate of the deviation between the terminator angle $(\varepsilon)$ and the magnetic declination $(\delta)$. The $\varepsilon$ is defined as a function of day of year $(D), \varepsilon=$ $23.5^{\circ} \sin \left(\frac{\pi(D-81)}{182.5}\right)$. In this study, we used $\delta=-0.67^{\circ}$ at an altitude of $350 \mathrm{~km}$, longitude of $100^{\circ} \mathrm{E}$, and latitude of $8.5^{\circ} \mathrm{N}$ (magnet-
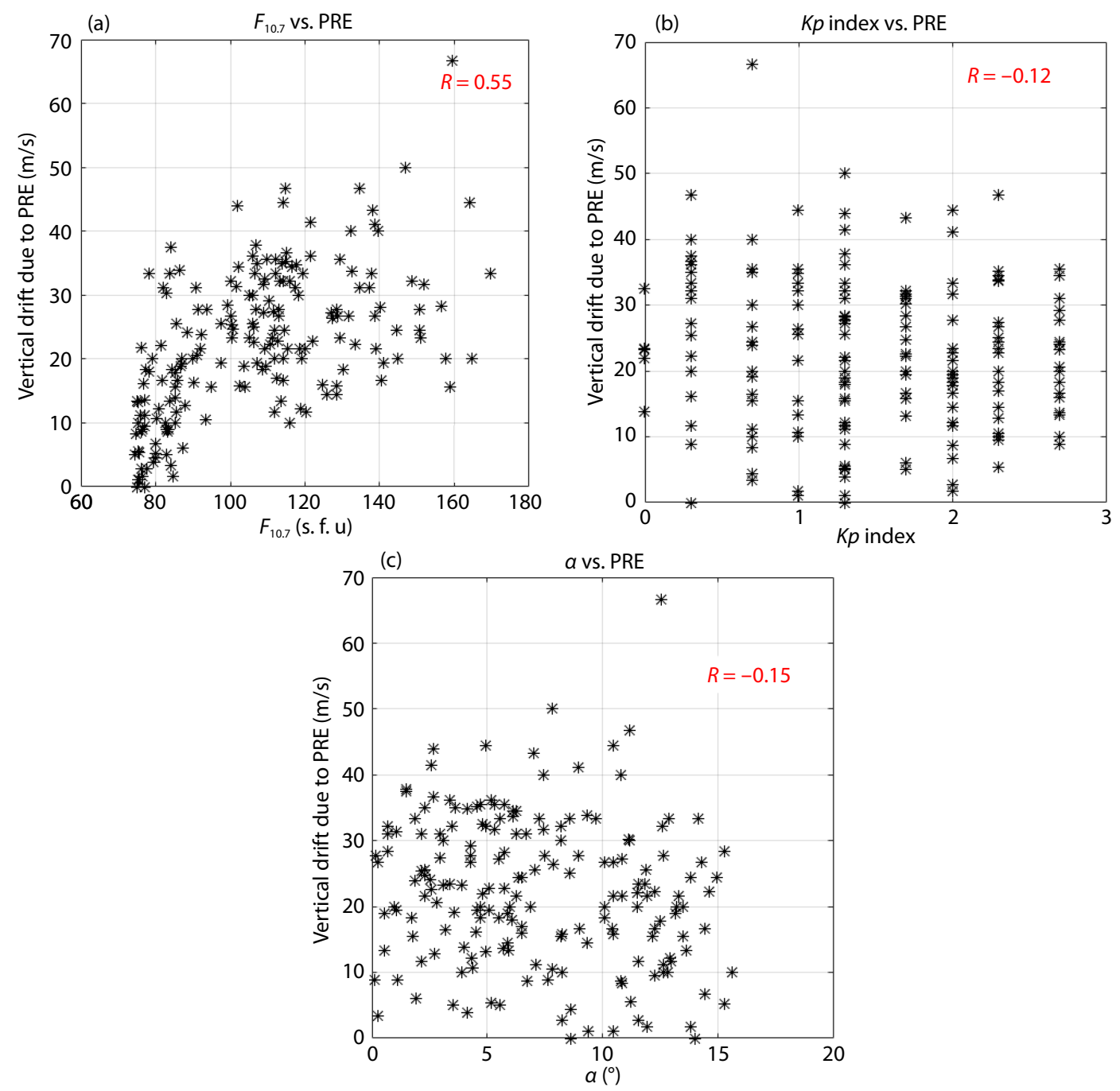

Figure 4. Scatter plot of PRE against (a) $F_{10.7}$, (b) $K p$ index, and (c) the angle $a$ between the magnetic field and solar terminator. $R$ in each panel is

the cross-correlation coefficient between the two parameters plotted in that panel. A detailed description of $a$ is described in the main text.

ic latitude: $\left.\sim 0^{\circ}\right) ; \delta$ is taken from the International Geomagnetic Reference Field (IGRF) 2013 model (Thébault et al., 2015).

Figure 4 summarizes the 187 days of PRE observation from ionosondes, presenting respectively in panels $4(a-c)$ the relationships between the PRE and the daily $F_{10.7}$, between the PRE and the $K p$ index, and between the PRE and $a$. In each panel, the value of $R$ indicates the cross-correlation coefficient of the relationship between the two parameters plotted in that panel. Here, we use $R$ to quantify how one parameter correlates with another parameter. Briefly, Figure 4 reports cross-correlation coefficients $(R)$ of $0.55,-0.12$, and -0.15 for the relationships of the PRE against the daily $F_{10.7}$, the $K p$ index, and $a$, respectively. Figure $4 a$ demonstrates that the PRE is positively correlated with the level of daily solar activity; Figure $4 \mathrm{~b}$ shows a significantly weaker, negative, correlation between the PRE and the magnetic activity; Figure 4c reveals an even weaker correlation, also negative, between the alignment of terminator angles-magnetic declination and the PRE. We interpret the results reported in Figure 4 as indicating that daily variation of PRE magnitude is significantly more influenced by solar activity than by magnetic activity or by and the variation 
of the angle between the solar terminator and the magnetic declination.

We now describe the result for the relationship between zonal neutral wind and PRE. The wind and the vertical drift due to PRE were observed simultaneously on 69 days by, respectively, the GOCE satellite and the ionosondes. Figure 5 presents a scatter plot of the zonal neutral wind against the PRE deduced from the ionosonde data. Each asterisk in Figure 5 represents one day's wind and PRE magnitudes. The black solid line in Figure 5 shows a linear regression between the wind and PRE data; the cross-correlation coefficient $(R)$ between the two parameters is approximately 0.42 . From the black line in Figure 5, the PRE strength can be seen statistically to increase from $\sim 13 \mathrm{~m} / \mathrm{s}$ to $\sim 26 \mathrm{~m} / \mathrm{s}$ as the speed of eastward winds increase from $\sim 75 \mathrm{~m} / \mathrm{s}$ to $\sim 150 \mathrm{~m} / \mathrm{s}$, reflecting the positive correlation between PRE magnitude and eastward wind velocity seen in Figure 5.

We next examine the relationship between the IEEJ and the PRE. Simultaneous measurements of IEEJ and PRE strengths were obtained on 107 days, allowing us to investigate statistically the effect of the EEJ on the PRE magnitude. Figure 6 shows a scatter plot between the IEEJ and PRE strengths data. Daily values of the IEEJ and the PRE strengths are represented by 107 asterisks, one for each day of simultaneous observation; the black solid line indicates the linear regression between the IEEJ and PRE strengths. The cross-correlation coefficient $(R)$ for the relationship between the IEEJ and the PRE data is approximately 0.47. Similar to the relationship between the wind and the PRE, here again the PRE strength is positively correlated with IEEJ strength, and with a comparable cross-correlation coefficient.

We found positive correlations between the wind and the PRE and between the IEEJ and the PRE in the data summarized in Figures 5 and 6, respectively. On the other hand, PRE strength is strongly affected by the variation of the daily solar activity, as shown in

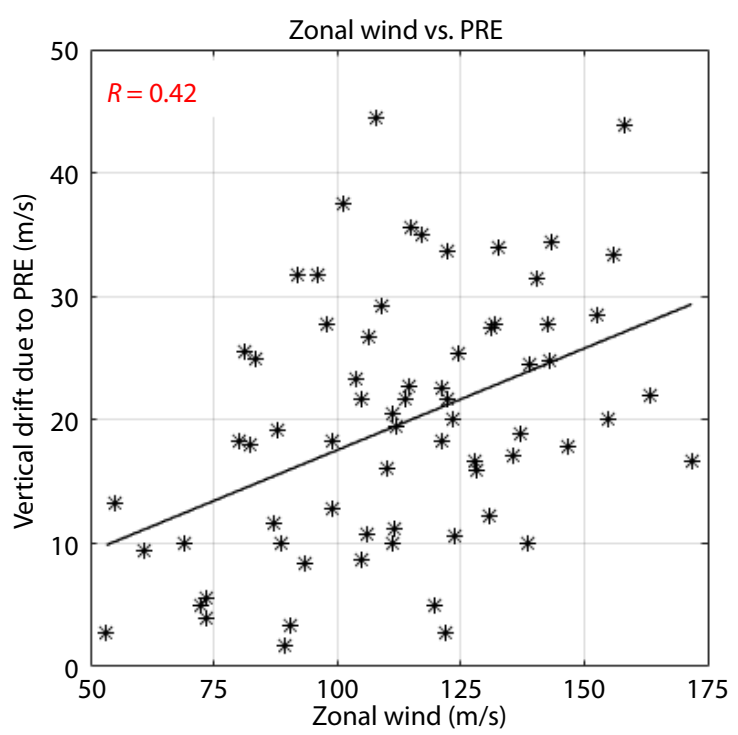

Figure 5. Scatter plot of zonal wind measured by the GOCE satellite against the PRE derived from ionosonde data. The black solid line indicates the linear regression of these data (asterisks); the crosscorrelation coefficient $(R)$ is 0.42 .
Figure 4. In fact, our observations show that the relationship between solar activity and the PRE has a higher cross-correlation coefficient than the coefficients associated with the PRE against the wind and against the EEJ. Furthermore, we need also to investigate whether solar activity affects the wind or the EEJ, or whether their influence is mostly independent of solar activity. We collected 74 days of wind observations and 119-days of the IEEJ; Figure 7 presents scatter plots of $F_{10.7}$ against zonal wind and IEEJ; in these plots, the cross-correlation coefficients between $F_{10.7}$ and wind and between the $F_{10.7}$ and the IEEJ are 0.08 and 0.31 , respectively. These $R$ values are weaker than those of the relationships of PRE against wind and PRE against EEJ, suggesting that the wind and EEJ do not strongly depend on solar activity. Therefore, we consider that the high positive correlations of the wind and EEJ to PRE (Figures 5 and 6) are not significantly affected by the positive correlation between solar activity and PRE strength.

Finally, Figure 8 presents the relationship between the eastward wind and the IEEJ. We were able to find just 28 days for which simultaneous observations of wind by the GOCE satellite and IEEJ by the magnetometers were available. The cross-correlation coefficient for the relationship between these limited wind and IEEJ data is positive but has a weaker $R$ value (0.26) than the positive $R$ coefficients reported above between the wind and the PRE and the IEEJ and the PRE. We thus suggest that the zonal wind and the IEEJ act substantially independently on the PRE.

\section{Discussion}

Our analysis finds positive correlations between the eastward neutral wind and the PRE and between the EEJ and the PRE (Figures 5 and 6). We infer that PRE magnitude is significantly affected by the eastward wind and the EEJ strength; stronger eastward wind and stronger EEJ appear to enhance the PRE mag-

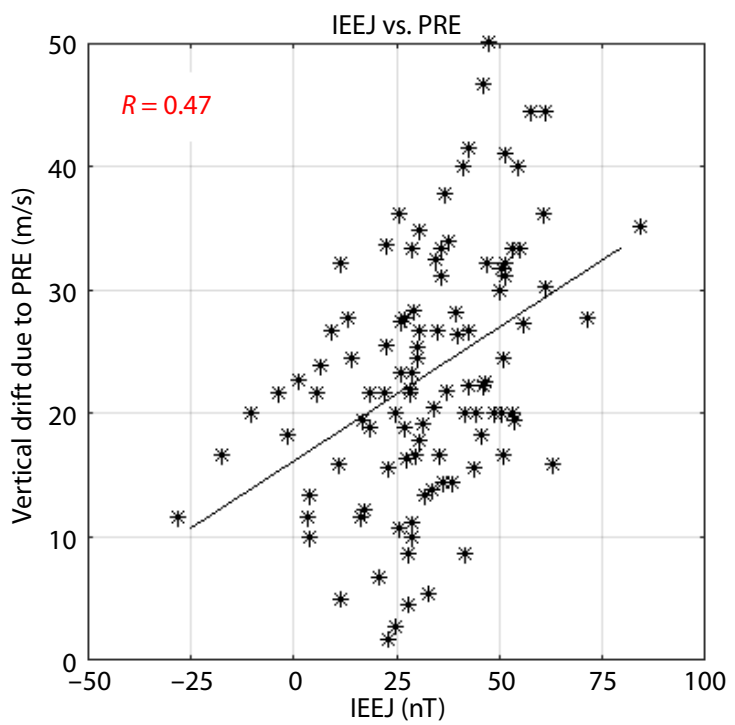

Figure 6. Scatter plot of IEEJ strength (estimated from magnetometer data) against PRE strength (derived from ionosonde data). The black solid line indicates the linear regression for the relationship between IEEJ and PRE strengths; its cross-correlation coefficient $(R)$ is 0.47 . 

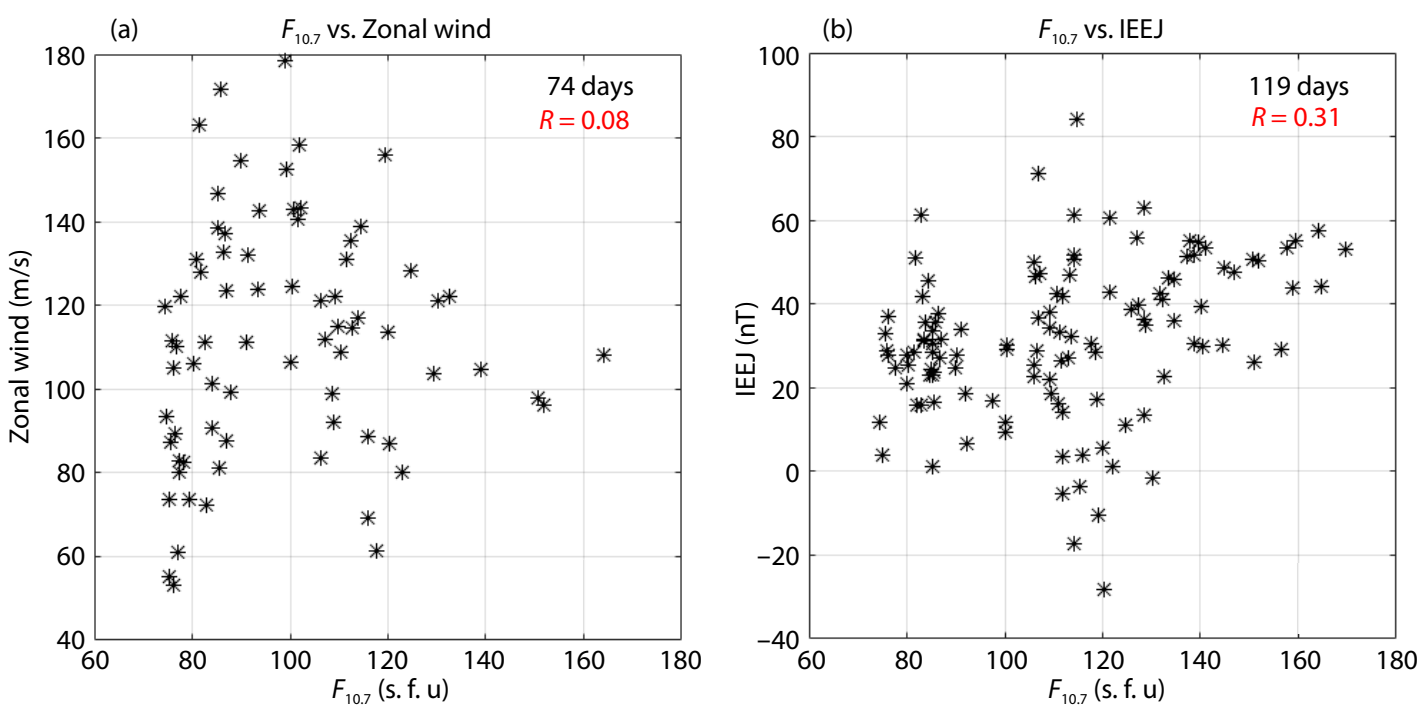

Figure 7. Scatter plots of $F_{10.7}$ against the zonal wind (a) and against IEEJ strength (b). The relationships between the $F_{10.7}$ and wind and between the $F_{10.7}$ and IEEJ have cross-correlation coefficients $(R)$ of 0.08 and 0.31 , respectively.

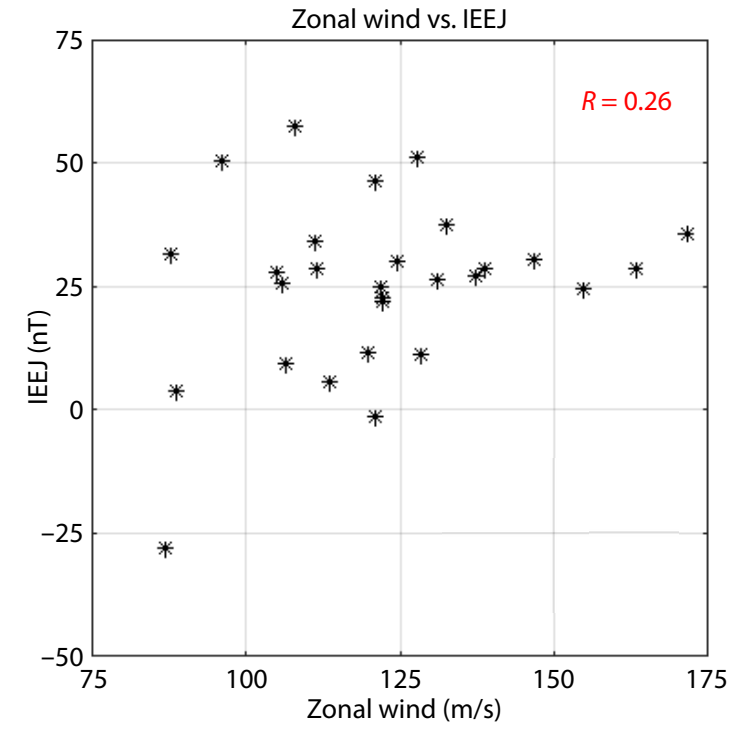

Figure 8. Scatter plot of the zonal wind from the GOCE satellite against the IEEJ strength from the magnetometers. The relationship between the wind and the IEEJ has a cross-correlation coefficient $(R)$ of 0.26 .

nitude. The cross-correlation coefficients for the relationships between the eastward wind and the PRE and between the EEJ and the PRE are comparable, suggesting that it is the balance between these two influences that is reflected in PRE magnitude variations.

The strong dependence of the PRE on daily variations of solar flux has long been recognized (e.g., Fejer et al., 1999; Huang CS and Hairston, 2015), but it is not clear how solar flux controls the PRE magnitude (Huang CS and Hairston, 2015). We want to emphasize that the effects of solar flux on the PRE magnitude are beyond the scope of this study, though our data certainly do confirm the importance of solar flux, finding it (Figure 4) to be significantly more important than the influences of magnetic activity and the angle between the solar terminator and the magnetic field. We ac- knowledge, therefore, that the PRE data used for the analyses presented in Figures 5 and 6 are not independent of but undoubtedly reflect the influence of daily solar activity. One could thus argue that the eastward neutral wind and the EEJ influences we report in this study could be seen simply as indirect influences of solar activity.

However, the analysis summarized in Figure 7 suggests that the wind and the EEJ effects could be at least somewhat independent of daily variations in solar activity; our findings are that daily variations of the wind and the EEJ do not correlate strongly with solar activity variations. In short: We suggest that the results summarized in Figures 5-7 argue that the influences of the wind and the EEJ on the PRE may be significantly independent of the wellknown influences of solar activity.

The causal relationship between the eastward neutral wind and the PRE strength can be explained by the role of the wind on the PRE mechanism through the $F$ region dynamo process (Rishbeth, 1971a, b; Farley et al., 1986; Eccles, 1998). The fundamental driver in the PRE mechanism is the eastward neutral wind through the $F$ region dynamo process (Eccles et al., 2015). The process of $F$ region dynamo actively driven by the eastward wind is briefly described as follows. The eastward wind in the equatorial $F$ region across the geomagnetic field lines generates an upward current. To maintain divergence-free current, the negative and positive charges are accumulated in the bottomside and topside $\mathrm{F}$ region, respectively, and the downward polarization electric field is then generated (Rishbeth, 1971a). This downward polarization electric field is an essential component in the PRE mechanism. Therefore, the positive correlation between the wind and the PRE in Figure 5 signifies that larger eastward wind could generate a stronger downward polarization electric field that substantiates to generate a larger PRE magnitude (Rishbeth, 1971b; Farley et al., 1986).

This study also emphasizes that the results presented in Figure 5 are strong observational evidence of the statistical relationship between the eastward neutral wind in the evening thermosphere 
and the PRE magnitude. Previous studies of the role of the eastward neutral wind on the PRE mechanism have employed models or numerical simulations (e.g., Eccles et al., 2015; Ghosh et al., 2020). In this study, wind data from the GOCE satellite has provided empirical evidence that stronger eastward neutral winds appear to generate larger PRE magnitudes.

Figure 6 summarizes our statistical investigation of the influence of EEJ on the PRE magnitude. We report a positive correlation between EEJ strength and PRE magnitude. Haerendel and Eccles (1992) proposed a mechanism for this influence that was reviewed comprehensively by Eccles et al. (2015): its fundamental driver is the upward $\mathrm{F}$ region dynamo current created by the eastward neutral wind in the sunset period, which Haerendel and Eccles (1992) suggested, could connect with the EEJ current from the $\mathrm{E}$ region to enhance the PRE magnitude. The positive correlation between EEJ strength and PRE magnitude found in this study offers supports for their proposed mechanism.

Our analysis suggests that both the eastward wind and the EEJ could participate significantly in the PRE mechanism. We also examined the relationship between the wind and the EEJ, finding a cross-correlation coefficient between them of approximately 0.26 , a value weaker than those between the wind and the PRE and the EEJ and the PRE. The weak correlation between wind and EEJ is explained by their different altitudes. The wind is in the bottomside $F$ region; the $E E J$ is an eastward current in the $E$ region. In short: Our analysis of the empirical data on which this study is based leads us to suggest that the wind and the EEJ influence the PRE magnitude relatively independently of each other.

In Figure 6, we note a few instances of negative IEEJ with positive PRE; these suggest that the PRE or eastward electric field in the dusk sector in the equatorial region can occur even when the EEJ is negative (westward EEJ current or counter EEJ). However, we point out that, in these instances of PRE with negative EEJ, PRE values are not large, e.g., below $30 \mathrm{~m} / \mathrm{s}$. Figure 8 records two points at which a negative EEJ is recorded with the wind still blowing eastward; these could be a clue to why the normal PRE (eastward electric field at dusk sector) can occur even under the condition of negative EEJ. Since both the eastward wind and EEJ are involved in the PRE mechanism, and both contribute equivalently and independently to the increase of the PRE amplitude, a weak PRE could result from an unusual balance between the two in which, despite the negative EEJ, the usually dominant eastward wind, the fundamental driver of the PRE mechanism through the $\mathrm{F}$ region dynamo process (Eccles, 1998; Eccles et al., 2015), could still generate the PRE (Rishbeth, 1971a, b; Farley et al., 1986). However, in such a situation the mechanism proposed by Haerendel and Eccles (1992) would not apply; instead a strengthened PRE, the combination of eastward wind and negative EEJ could be expected to result in a weaker PRE magnitude, which indeed appears to have been observed.

Recently, Ghosh et al. (2020) demonstrated the use of the GAIA model to examine the roles of the zonal neutral wind and the EEJ on the daily variation of the PRE magnitude in the Southeast Asian longitude sector and equinoctial months - the same region and seasons as the data analyzed in this study; thus our observa- tions invite comparison to the GAIA simulations, which found cross-correlation coefficients for the relationships between the wind and the PRE and between the EEJ and the PRE of approximately 0.5 and 0.4 , respectively. These values support our observational conclusions that the wind and the EEJ act in a balanced manner in affecting the PRE magnitude. The consistency between the results of Ghosh et al. (2020) and our findings suggests that the GAIA model can be used to study the coupling of neutral thermosphere-plasma ionosphere in relation to the equatorial PRE, the equatorial electrojet current in the $E$ region, and the thermospheric neutral wind.

\section{Conclusion}

We have investigated statistically the relationships between the thermospheric neutral wind and the PRE magnitude and between the EEJ and the PRE magnitude, employing observations in Southeast Asia during March-April and September-October from 2010 to 2013. PRE magnitudes were derived from data collected by three ionosondes - at Chumphon, Thailand, at Bac Lieu, Vietnam, and at Cebu, Philippines. Data characterizing the thermospheric neutral wind at the bottomside $F$ region in the evening sector were retrieved from in-situ measurements made aboard the GOCE satellite. Two magnetometers, one located at the equatorial station at Phuket in Thailand and another situated at the off-equatorial station at Kototabang in Indonesia, supplied data used to derive the EEJ strength. The relationships between the eastward neutral wind and the PRE magnitude and between the EEJ strength and the PRE magnitude were found to have cross-correlation coefficients $(R)$ of 0.42 and 0.47 , respectively. We also find that the relationship between the eastward wind and the EEJ has a weaker positive correlation $(R=0.26)$. Thus, the influences of wind and EEJ are relatively independent of each other.

Previous studies of the relationship between the eastward wind and the PRE have been carried out primarily by numerical simulations or models (e.g., Eccles et al., 2015; Ghosh et al., 2020). This study, based on empirical data, finds a positive correlation between the strength of the PRE and the magnitude of the eastward wind in the evening thermosphere. Moreover, the data strongly suggest that this influence is significantly independent of the influence from the EEJ, both influences being positively correlated with PRE strength. Our results support the ideas that both the eastward neutral wind and the eastward current of EEJ are involved in the PRE mechanism, as proposed by previous investigators (see Rishbeth, 1971b; Farley et al., 1986; Haerendel and Eccles, 1992; Eccles, 1998; Eccles et al., 2015). We note that the correlation coefficients of the relationships between the wind and the PRE and between the EEJ and the PRE are of similar magnitude, suggesting that each can independently drive the PRE magnitude. Stronger eastward winds and/or stronger positive EEJs can enhance PRE magnitudes. Finally, it should be noted that the correlation between the eastward wind in the $F$ region and the EEJ in the $E$ region is relatively weak, perhaps explaining how the effects of these two parameters on the PRE magnitude could be significantly independent. 


\section{Acknowledgments and Data Sources}

The data used in this study from the ionosondes and the magnetometer at Phuket belong to the SEALION project of National Institute of Information and Communications Technology (NICT), Japan, and can be accessed at https://aer-nc-web.nict.go.jp/ sealion/. The $F_{10.7}$ and $K p$ index data were obtained from the OMNIWEB website, https://omniweb.gsfc.nasa.gov/form/dx1.html. PA carried out the data analysis in this study as well as wrote and organized the manuscript. All co-authors helped review the manuscript. HL also contributed to providing the wind data measured by the GOCE satellite. KH helped prepare the SEALION data. Data from the magnetometer at Kototabang, Indonesia, can be accessed through the website of the ERG (Exploration of energization and Radiation in Geospace) science center. This work is supported by the program of Follow-up Research Guidance of Japan Student Services Organization (JASSO) in 2019, the Indonesian Ministry of Research and Technology and National Research and Innovative Agency (Kementerian RISTEK-BRIN) through the program of Pusat Unggulan Iptek (PUI) in 2019, and the Space Science Center of LAPAN through a research grant program in 2020. HL acknowledges support from JSPS KAKENHI Grants 18H01270, 18H04446, and 17KK0095, and JRPs-LEAD with DFG. KH was partially supported by JSPS KAKENHI Grant Number 20H00197. PJ was supported by the Program Management Unit for Human Resources \& Institutional Development, Research and Innovation (grant number B05F630018).

\section{References}

Abadi, P., Otsuka, Y., Shiokawa, K., Husin, A., Liu, H. X., and Saito, S. (2017). Equinoctial asymmetry in the zonal distribution of scintillation as observed by GPS receivers in Indonesia. J. Geophys. Res.: Space Phys., 122(8), 8947-8958. https://doi.org/10.1002/2017JA024146

Abadi, P., Otsuka, Y., Supriadi, S., and Olla, A. (2020). Probability of ionospheric plasma bubble occurrence as a function of pre-reversal enhancement deduced from ionosondes in Southeast Asia. AIP Conf. Proc., 2226(1), 050001. https://doi.org/10.1063/5.0002321

Bittencourt, J. A., and Abdu, M. A. (1981). A theoretical comparison between apparent and real vertical ionization drift velocities in the equatorial $F$ region. J. Geophys. Res.: Space Phys., 86(A4), 2451-2454. https://doi.org/10.1029/JA086iA04p02451

Burke, W. J., Huang, C. Y., Gentile, L. C., and Bauer, L. (2004). Seasonallongitudinal variability of equatorial plasma bubbles. Ann. Geophys., 22(9), 3089-3098. https://doi.org/10.5194/angeo-22-3089-2004

Carter, B. A., Retterer, J. M., Yizengaw, E., Groves, K., Caton, R., McNamara, L., Bridgwood, C., Francis, M., Terkildsen, M., ... Zhang, K. (2014). Geomagnetic control of equatorial plasma bubble activity modeled by the TIEGCM with Kp. Geophys. Res. Lett., 41(15), 5331-5339. https://doi.org/10.1002/2014GL060953

Dabas, R. S., Singh, L., Lakshmi, D. R., Subramanyam, P., Chopra, P., and Garg, S. C. (2003). Evolution and dynamics of equatorial plasma bubbles: relationships to ExB drift, postsunset total electron content enhancements, and equatorial electrojet strength. Radio Sci., 38(4), 1075. https://doi.org/10.1029/2001RS002586

Doornbos, E., van den ljssel, J., Lühr, H., Förster, M., and Koppenwallner, G. (2010). Neutral density and crosswind determination from arbitrarily oriented multiaxis accelerometers on satellites. J. Space. Rock., 47(4), 580-589. https://doi.org/10.2514/1.48114

Eccles, J. V. (1998). Modeling investigation of the evening prereversal enhancement of the zonal electric field in the equatorial ionosphere. J.
Geophys. Res.: Space Phys., 103(A11), 26709-26719.

https://doi.org/10.1029/98JA02656

Eccles, J. V., St. Maurice, J. P., and Schunk, R. W. (2015). Mechanisms underlying the prereversal enhancement of the vertical plasma drift in the low-latitude ionosphere. J. Geophys. Res.: Space Phys., 120, 4950-4970. https://doi.org/10.1002/2014JA020664

Farley, D. T., Bonelli, E., Fejer, B. G., and Larsen, M. F. (1986). The prereversal enhancement of the zonal electric field in the equatorial ionosphere. J. Geophys. Res.: Space Phys., 91(A12), 13723-13728. https://doi.org/10.1029/JA091iA12p13723

Fejer, B. G. (1997). The electrodynamics of the low-latitude ionosphere: recent results and future challenges. J. Atmos. Sol. Terr. Phys., 59(13), 1465-1482. https://doi.org/10.1016/S1364-6826(96)00149-6

Fejer, B. G., Scherliess, L., and de Paula, E. R. (1999). Effects of the vertical plasma drift velocity on the generation and evolution of equatorial spread $F$. J. Geophys. Res.: Space Phys., 104(A9), 19859-19869. https://doi.org/10.1029/1999JA900271

Ghosh, P., Otsuka, Y., Mani, S., and Shinagawa, H. (2020). Day-to-day variation of pre-reversal enhancement in the equatorial ionosphere based on GAIA model simulations. Earth Planets Space, 72(1), 93. https://doi.org/10.1186/s40623-020-01228-9

Haerendel, G., and Eccles, J. V. (1992). The role of the equatorial electrojet in the evening ionosphere. J. Geophys. Res.: Space Phys., 97(A2), 1181-1192. https://doi.org/10.1029/91JA02227

Huang, C. S., and Hairston, M. R. (2015). The postsunset vertical plasma drift and its effects on the generation of equatorial plasma bubbles observed by the C/NOFS satellite. J. Geophys. Res.: Space Phys., 120(3), 2263-2275. https://doi.org/10.1002/2014JA020735

Huang, C. S. (2018). Effects of the postsunset vertical plasma drift on the generation of equatorial spread F. Prog. Earth Planet. Sci., 5(1), 3. https://doi.org/10.1186/s40645-017-0155-4

Kelley, M. C. (2009). The Earth's lonosphere: Plasma Physics and Electrodynamics (2nd ed). San Diego: Academic Press.

Kelley, M. C., Ilma, R. R., and Crowley, G. (2009). On the origin of pre-reversal enhancement of the zonal equatorial electric field. Ann. Geophys., 27(5), 2053-2056. https://doi.org/10.5194/angeo-27-2053-2009

Liu, H. X., Watanabe, S., and Kondo, T. (2009). Fast thermospheric wind jet at the Earth's dip equator. Geophys. Res. Lett., 36(8), L08103. https://doi.org/10.1029/2009GL037377

Liu, H. X., Doornbos, E., and Nakashima, J. (2016). Thermospheric wind observed by GOCE: wind jets and seasonal variations. J. Geophys. Res.: Space Phys., 121(7), 6901-6913. https://doi.org/10.1002/2016JA022938

Liu, H. X., Pedatella, N., and Hocke, K. (2017). Medium-scale gravity wave activity in the bottomside $F$ region in tropical regions. Geophys. Res. Lett., 44(14), 7099-7105. https://doi.org/10.1002/2017GL073855

Maruyama, T., Kawamura, M., Saito, S., Nozaki, K., Kato, H., Hemmakorn, N., Boonchuk, T., Komolmis, T., and Ha Duyen, C. (2007). Low latitude ionosphere-thermosphere dynamics studies with inosonde chain in Southeast Asia. Ann. Geophys., 25(7), 1569-1577. https://doi.org/10.5194/angeo-25-1569-2007

Nozaki, K. (2009). FMCW ionosonde for the SEALION project. J. Natl. Inst. Inf. Commun. Technol., 56(1-4), 287-298.

Raghavarao, R., Wharton, L. E., Spencer, N. W., Mayr, H. G., and Brace, L. H. (1991). An equatorial temperature and wind anomaly (ETWA). Geophys. Res. Lett., 18(7), 1193-1196. https://doi.org/10.1029/91GL01561

Rishbeth, H. (1971). The F-layer dynamo. Planet. Space Sci., 19(2), 263-267. https://doi.org/10.1016/0032-0633(71)90205-4

Rishbeth, H. (1971). Polarization fields produced by winds in the equatorial $F$ region. Planet. Space Sci., 19(3), 357-369. https://doi.org/10.1016/00320633(71)90098-5

Seo, J., Walter, T., Chiou, T. Y., and Enge, P. (2009). Characteristics of deep GPS signal fading due to ionospheric scintillation for aviation receiver design. 
Radio Sci., 44(1), RS0A16. https://doi.org/10.1029/2008rs004077

Thébault, E., Finlay, C. C., Beggan, C. D., Alken, P., Aubert, J., Barrois, O., Bertrand, F., Bondar, T., Boness, A., ... Zvereva, T. (2015). International geomagnetic reference field: the 12th generation. Earth Planet Space, 67(1), 79. https://doi.org/10.1186/s40623-015-0228-9

Tulasi Ram, S., Rama Rao, P. V. S., Prasad, D. S. V. V. D., Niranjan, K., Raja Babu, A., Sridharan, R., Devasia, C. V., and Ravindran, S. (2007). The combined effects of electrojet strength and the geomagnetic activity ( $K_{p}$-index) on the post sunset height rise of the F-layer and its role in the generation of ESF during high and low solar activity periods. Ann. Geophys., 25(9), 2007-2017. https://doi.org/10.5194/angeo-25-2007-2007

Uemoto, J., Maruyama, T., Saito, S., Ishii, M., and Yoshimura, R. (2010). Relationships between pre-sunset electrojet strength, pre-reversal enhancement and equatorial spread-F onset. Ann. Geophys., 28(2), 449-454. https://doi.org/10.5194/angeo-28-449-2010

Wernik, A. W., and Liu, C. H. (1974). lonospheric irregularities causing scintillation of $\mathrm{GHz}$ frequency radio signals. J. Atmos. Terr. Phys., 36(5), 871-879. https://doi.org/10.1016/0021-9169(74)90032-4 